\title{
A LA SOMBRA DE HOBBES Sobre la ideología de la separación de poderes
}

\author{
Andrea Greppi \\ Universidad Carlos III de Madrid
}

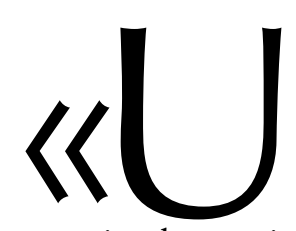

na Sociedad en que no esté establecida la garantía de los Derechos, ni determinada la separación de los Poderes, carece de Constitución», se lee en el art. 16 de la Declaración de derechos del hombre y el ciudadano de 1789. De los dos ingredientes de esta fórmula, que hemos de entender como dos piezas complementarias de un mismo engranaje, al segundo le ha tocado peor suerte que al primero. No se ha visto desmentido, pero sus logros han sido inciertos y a menudo controvertidos. Tanto es así que, al cabo de un complicado proceso de encaje, ha acabado quedando en un segundo plano.

Si me permito traer a este diálogo sobre la obra de Francisco LAPORTA y Liborio HIERRO un lugar común sobre el que no parece haber demasiadas cosas por descubrir es para sugerir que, a pesar de todo, no sería tan mala idea volver sobre este punto y valorar algunos aspectos del marco ideológico de fondo que suele darse por descontado en los debates sobre las perspectivas del constitucionalismo contemporáneo. Un marco - y anticipo así mi sospecha- que podría estar evolucionando rápidamente. En lo que sigue, por tanto, no voy a fijarme en ningún trabajo en particular de los autores que son objeto de nuestra admiración y de nuestro homenaje. Me tomaré la libertad de leer sus escritos desde fuera y desde lejos. Aludiendo a algunas de sus tesis más conocidas, me preguntaré cómo es que en los debates sobre las tensiones a las que están sometidas nuestras democracias, así como en las proyecciones sobre la constitucionalización del (des)orden post-nacional, el ideal de la separación de poderes ha dejado de ser tratado como una de las dos componentes esenciales de una constitución democrática, según afirmaban los revolucionarios del '89, y se ha convertido en una variable menor en un proceso centrado básicamente en el eje que va de los derechos fundamentales a la legitimidad. Con la brevedad del caso, comenzaré recordando algunos hitos que han producido este resultado.

Pese a su venerable genealogía, la trayectoria de la separación de poderes comenzó a torcerse desde el comienzo, en su primera y más prestigiosa afirmación histórica. Al tratar de la distribución de las partes constitutivas del gobierno de la Federación, MADISON descartaba con énfasis una interpretación demasiado estrecha de la «máxima política según la cual los departamentos legislativo, ejecutivo y judicial deben ser distintos y diferentes». Lo que la Constitución establece, a su juicio, es que los departamentos deben estar distribuidos y mezclados, sin comprometer la «simetría y belleza» del arreglo, pero asegurándose de que las «partes esenciales del edificio» no queden expuestas al peligro «de verse aplastadas por el peso desproporcionado de otras». 
El blanco de esta puntualización era evidentemente MONTESQUIEU, «el oráculo que siempre se cita y consulta». De un examen atento de la constitución británica —escribe MADISON — «es posible inferir con claridad que al decir: "No puede haber libertad donde los poderes legislativo y ejecutivo se hallan unidos en la misma persona o en el mismo cuerpo de magistrados", o "si el poder de juzgar no está separado de los poderes legislativo y ejecutivo", [MONTESQUIEU] no quería decir que estos departamentos no deberían tener una intervención parcial en los actos del otro o cierto dominio sobre ellos. Su idea, [...] no puede tener más alcance que este: que donde todo el poder de un departamento es ejercido por quienes poseen todo el poder de otro departamento, los principios fundamentales de una constitución libre se hallan subvertidos» (1788, XLVIII). Los Padres Fundadores nos legaron un problema del que no acabamos nunca de librarnos: tan importante es lograr que cada uno de los poderes pueda ejercer de contrapeso a los restantes, como establecer las garantías para su recíproca independencia. No basta, por tanto, separar los poderes, como se supone que dice la versión más esquemática de la fórmula. La relación entre poderes es bastante más complicada.

Cien años más tarde, la controversia sobre el capítulo XI del Espíritu de las Leyes, con sus equívocas concesiones estamentales, seguía sin haberse despejado. La contradicción era patente. «Para muchos bien intencionados —escribía Leon DuguIT en 1893 - la separación de poderes es la condición esencial de cualquier gobierno ponderado, el principio mismo de cualquier régimen representativo basado en la soberanía popular, la garantía necesaria y común de los intereses colectivos y de los derechos individuales; es, en definitiva, el ideal político que los pueblos y legisladores deben perseguir sin tregua». Pero es un ideal que encierra también «una singular ilusión». Y es que, desde el punto de vista teórico, una separación «absoluta» entre los poderes no puede concebirse. «El cumplimiento de cualquier función del Estado se traduce siempre en el dictado de una orden o en la adopción de un acuerdo, es decir, en un acto de voluntad, en una manifestación de su personalidad». Por eso el gobierno parlamentario, «la forma política mejor adaptada a la democracia representativa», la única forma política que, «hasta la fecha» $\mathrm{y}$ «a pesar de lo que se diga», garantiza «en un gran país» los derechos «de la colectividad y del individuo», «no reposa sobre la separación de poderes, sino, por el contrario, sobre su colaboración y su solidaridad» (1996:3).

Pasados cien años más, la incomodidad ante las formulaciones más estrictas de la separación sigue tan viva como antes. En un texto de referencia de finales de los años sesenta, y en el epílogo redactado en el cambio de siglo, M. J. C. VILE no podía más que constatar la intensidad de las mutaciones que comprometen las premisas fundamentales de la separación. Aunque «la burocracia lleva acompañándonos más de doscientos años, el Estado administrativo contemporáneo muestra una complejidad estructural tan extremada y una proliferación de normas tal que el antiguo concepto del "ejecutivo" como un conjunto de funcionarios que ponen en ejercicio los mandatos del legislativo bajo la dirección de los ministros ya no tiene valor real». Los desajustes de la teoría tradicional, «que divide los poderes y funciones en tres categorías», son patentes. La cuestión está en identificar «los métodos apropiados para controlar cada una de las ramas», considerando «que no pued[e] confiarse una función única y exclusiva a cualquiera de ellas». Por supuesto, siempre cabe la posibilidad de identificar cuatro funciones abstractas — la creación de normas, la función discrecional, la aplicación de 
normas y el arbitrio conforme a las normas-; pero la pretensión de «adjudicarlas en exclusiva» a poderes distintos, carece de sentido. De hecho, «toda muestra de comportamiento humano implica el ejercicio de las cuatro funciones en mayor o menor grado» (2007: 404-407).

Esta última idea, que podríamos formular como la tesis del solapamiento fisiológico de las funciones, cuestiona el núcleo mismo de la separación. Su repercusión es amplísima. Recuérdese por ejemplo un conocido ensayo sobre la nueva división de poderes en el que Bruce ACKERMAN propone una diversificación de los equilibrios, acorde a las exigencias funcionales de una estructura institucional mucho más compleja que la existente en el pasado. En el modelo del «parlamentarismo acotado» habría un poder central —una cámara legislativa electa - «contrapesado por un conjunto de poderes específicos», entre los que habría un sistema de «referéndum en serie», con el aval de un tribunal constitucional, un «senado federal subordinado», un «poder supervisor de la autoridad burocrática», que vigila actividad del gobierno, un «poder supervisor de la regulación», que contra la burocracia, un «poder supervisor de la democracia», que vela por la participación, y un «poder de justicia distributiva» centrado, por si todo lo anterior no fuera todavía suficiente, «en la provisión económica mínima para aquellos ciudadanos capaces de defender sus derechos políticamente» (2007: 124-135). Más allá de la evidente provocación, ACKERMAN está reconociendo que la experiencia constitucional estadounidense, la más cercana al proyecto de la separación tripartita, pudo ser adecuada en aquel tiempo y lugar, bajo determinadas condiciones contextuales, pero puede haber dejado de serlo en un contexto distinto. No será, por tanto, demasiado prudente empeñarse en reproducirlo a toda costa.

Vayamos entonces, sin dilatar este recorrido, al caso que nos interesa. Porque, como se sugería al comienzo, el propósito de esta nota no es otro que el de intentar poner en perspectiva algunos compromisos ideológicos de fondo que respaldan la obstinada insistencia, que algunos considerarán incluso intempestiva, en las técnicas diseñadas para la distribución y control recíproco entre los poderes. Una opción que suele asociarse - no hace falta decirlo- a la defensa de ciertos aspectos de una concepción iuspositivista del derecho. Reconocemos en esta actitud la tenaz desconfianza ante las pleamares racionalizadoras del constitucionalismo más vanguardista, o ante el sueño de quienes pretenden ampliar sin tregua las lindes del coto vedado de los principios y los derechos. Una opción que explica las ventajas de decantarse por un enfoque parsimonioso en el debate sobre los contenidos morales de una constitución democrática, que esquiva la referencia permanente a sus ingredientes más densos, y que busca el apoyo de las modestas cualidades formales de un derecho de reglas: la estabilidad, la publicidad, la no retroactividad. Es la disposición de quienes prefieren no dejarse seducir por los embrujos del elixir constitucional, la poderosísima pócima que proporciona una justificación exhaustiva para todas y cada una de las decisiones que conforman el ordenamiento, y ponen el foco en la previsibilidad de la conducta de «las agencias que han de proceder a aplicar por la fuerza las pautas contenidas en las reglas» (LAPORTA, 2007: 70).

Por supuesto, no es el lugar para hacer pronósticos sobre el efecto de las estrategias constitucionales que se desprenden de estas actitudes. En concreto, no merece la pena especular sobre cuál de estos distintos enfoques sobre el núcleo del constitucio- 
nalismo promoverá una mejora en la calidad de las decisiones, sea cual sea el criterio que utilicemos para distinguir entre decisiones «buenas» y «malas». Esta será, en gran parte, una cuestión empírica. El punto está en saber si contamos con indicios que avalen nuestra «intuición embrionaria» sobre la situación presente (LAPORTA, 2007: 14). Porque, como antes decía, buena parte del debate sobre las perspectivas del constitucionalismo nuevo y viejo, se ventila en el plano de los diagnósticos preliminares. Y es aquí donde se sitúa precisamente, frente al nuevo sentido común, que tiende a desplazarlas, la invitación a reconsiderar el valor de las reglas que distribuyen poderes. Mi impresión, al respecto, es que deberíamos tener presente que la marea de los contenidos sustanciales del constitucionalismo puede subir o bajar dependiendo de determinadas circunstancias del contexto y que, en función de esas oscilaciones, y en previsión de la próxima bajamar, nuestro problema principal no puede ser más que el de saber si en un futuro más o menos lejanos tendremos calado suficiente para que el barco quede a flote. En otros términos, y por razones que merecería la pena reconstruir en detalle, creo que el debate sobre la fisiológica confusión de las funciones, que sostiene la hipótesis de la feliz cooperación entre los poderes, se ha vuelto inaplazable.

Valga como ejemplo de este cambio de perspectiva - uno de tantos que vendrían a cuento- un escrito de Joseph WEILER sobre ciertas tendencias del fondo que han llevado a un enquistamiento en los problemas de legitimación en la Unión Europea. Tres fueron los canales por los que se pensaba que habría debido discurrir el proceso de integración y todos ellos — apunta WEILER (2012) — están aproximándose a un punto crítico. El primero de ellos se alimentaba de las tradicionales fuentes de legitimidad procedimental, de donde provenían los inputs del proceso democrático. El problema actual, en este ámbito, ya no está tanto en la creciente desafección de la ciudadanía respecto de las políticas europeas, sino más bien en el hecho de que, desmintiendo las previsiones iniciales, la Unión encuentra fuertes dificultares a la hora de «desarrollar estructuras y procesos que repliquen adecuadamente, o "traduzcan", [...] los todavía imperfectos hábitos de control gubernamental, rendición de cuentas ante el Parlamento y responsabilidad administrativa que tienen lugar, en modalidades distintas, en los Estados-miembro». A estas alturas, la pregunta más acuciante es si será suficiente fabricar una voluntad política más sólida que la existente para conseguir invertir la tendencia, o si la falta de voluntad no es más que el producto de unas condiciones objetivas en las que una voluntad semejante no tiene visos de llegar a formarse. La segunda fuente histórica de legitimación estaba relacionada con la capacidad de la Unión para proveer prosperidad, estabilidad y seguridad, entre otros bienes que constituyen los principales output del proceso político. Independientemente de los muchos desarrollos teóricos que se han producido en esta materia, la dinámica de integración se ha visto profundamente afectada desde el momento en que la Unión dejó de ser percibida por legos y expertos como el resultado de un juego en el que todos ganan y se convirtió, por las razones que fueran, en baluarte al servicio de las políticas de la austeridad, y de otros desastres similares. El proyecto de integración contaba, además, con una tercera fuente de legitimación, aparentemente secundaria respecto de las anteriores, pero que tenía la máxima importancia no solo para construir un relato histórico creíble de la unificación, sino también — subraya WEILER - para avalar opciones específicas de diseño institucional. El ideal de una unión cada vez más estrecha entre los pueblos se presentaba como la mejor herramienta para la realización de la Visión, 
el Proyecto, la Promesa - fatalmente con mayúsculas - de una Europa pacífica y próspera, el faro que habría iluminado el camino de los pueblos civilizados, como se lee en la Declaración de SCHUman, un documento profético que prefiguraba las esencias del método comunitario. Esta componente teleológica, y en último término mesiánica, fue depositándose en el código genético de un proceso instituyente que nunca se llegaría a cerrarse definitivamente. Supuestamente, es ahí donde radicaba su fuerza. No hace falta detenerse en mostrar que un enfoque como este, en los tiempos que corren, ha quedado gravemente dañado.

Salvando las distancias, e intentando reconstruir de la forma más sintética las intuiciones que acabaron descabalgando la apuesta del ' 89 por el doble engranaje de los derechos y la separación de poderes se podría aventurar la hipótesis de una convergencia entre estas tres dimensiones de legitimación. Durante décadas estuvo vigente en cierta subterránea creencia en que la dinámica del proceso político habría acabado orientándose, por caminos a veces inescrutables, pero atendiendo a una fuerza inexorable, hacia el descubrimiento de las soluciones «correctas», que a su vez no podían sino impulsar un consenso integrador. En particular, se creía que bastaba aumentar la participación y la capacidad para que los inputs de los actores sociales confluyeran armónicamente, aumentando la confianza de los ciudadanos en el sistema; que bastaba elevar la calidad argumentativa del proceso de toma de decisiones para obtener una mejora equivalente en la calidad epistémica de los outputs, la cual, a su vez, sería inmediatamente aplaudida por extensas mayorías sociales; y, finalmente, que bastaba reforzar los mecanismos de identificación colectiva en torno a la promesa de que algún día llegaran a cumplirse los ideales que decimos compartir, para asegurar en el largo plazo la estabilidad del sistema. La erosión de los postulados epistémicos que están en la base estas creencias - es un punto con amplias repercusiones filosóficas, que solamente puedo mencionar- deja el terreno despejado para que el péndulo del constitucionalismo pueda tomar el camino inverso, moviéndose de la sustancia a la forma, si se me permite el uso de una terminología tan burda, y vuelva a poner sobre la mesa la pregunta por la distribución de los poderes.

Podrá replicarse enseguida que la reflexión de WEILER se refiere a cosas que suceden en lugares remotos, que nada tienen que ver con el terreno firme en que hunden sus raíces las constituciones nacionales, donde los legisladores son soberanos y los jueces argumentan a conciencia. Utilizándola para otros fines, estaríamos incurriendo en una suerte de domestic fallacy invertida, que pasa por alto mil diferencias. La sospecha, sin embargo, es que la epidemia exterior sea una anticipación de lo que pudiera suceder de puertas adentro si el virus se extendiera y acabara contagiando, con las inevitables adaptaciones, los supuestos tácitos que impulsaron la marea constitucionalista. No sería extraño que, con tanto viaje, el virus experimentara una mutación ulterior, que lo hiciera inmune a los antibióticos disponibles. Constatada la volatilidad de los inputs y la incertidumbre de los outputs, y finiquitada la promesa mesiánica, deberíamos centrarnos en indagar si es razonable esperar que las vías exploradas por el nuevo constitucionalismo sigan trayendo en el futuro una «inyección de racionalidad» en el sistema jurídico y político comparable a la que produjeron en el pasado reciente (ATIENZA, LAPORTA, 2008: 53). Volveríamos a plantearnos entonces, en un contexto de discusión diferente, la conveniencia de reivindicar un derecho de reglas, que aspire a 
establecer, en lo posible, limites ciertos en el ejercicio de la autoridad. Nos ubicaríamos, una vez más, en compañía de LAPORTA, y con las modulaciones liberales del caso, «a la sombra de Hobbes» (2005: 265).

\section{BIBLIOGRAFÍA}

ACKerman, B., 2007: La nueva división de poderes, México: FCE.

ATIENZA, M., y LAPORTA, F., 2008: «Imperio de la ley y constitucionalismo», El Cronista del Estado Social y Democrático de Derecho, núm. 0, 307-326.

Duguit, L., 1996: La separación de poderes y la Asamblea Nacional de 1789, Madrid: Centro de Estudios Constitucionales (ed. orig. 1893).

LAPORTA, F., 2005: «Globalización e imperio de la ley. Algunas dudas westfalianas», Anales de la Cátedra Francisco Suárez, núm. 39, 243-265.

- 2007: Imperio de la ley, Madrid: Trotta.

Madison, J.; Hamilton, A., y Jay, J., 1788: Federalist Papers, ed. esp. El Federalista, México: FCE, ${ }^{2} 2001$.

VILE, M. J. C., 2007: Constitucionalismo y separación de poderes, Madrid: Centro de Estudios Políticos y Constitucionales.

WEILER, J., 2012: «In the face of crisis. Input legitimacy, output legitimacy and the political messianism of European integration», Journal of European Integration, 34, 7, 825-841. 